Check for updates

Cite this: RSC Adv., 2017, 7, 48989

Received 22nd August 2017

Accepted 13th October 2017

DOI: $10.1039 / \mathrm{c} 7 \mathrm{ra09285g}$

rsc.li/rsc-advances

\section{Redox-active copper triangles as an enzymatic molecular flask for light-driven hydrogen production $\uparrow$}

\author{
Liang Zhao, Dianwei Wei, Feili Zhang, Cheng He, (D) Sijia Zheng \\ and Chunying Duan (D) *
}

\begin{abstract}
A positively charged redox-active metal-organic triangle containing three redox-active copper centres was developed to encapsulate anionic organic dyes (fluorescein) through a weak host-guest interaction for photocatalytic hydrogen production. The unique geometry enforces a distorted square planar coordination suitable for proton reduction. Control experiments with a mononuclear copper complex as a reference photocatalyst and inactive ATP as an inhibitor were performed to confirm this enzymatic photocatalytic behaviour.
\end{abstract}

The development of catalytic synthetic methods inspired by natural enzyme prototypes that react under an ambient atmosphere and use benign solvents and clean energy is a major endeavour in synthetic chemistry. ${ }^{1-4}$ To match the efficiency and selectivity of enzymatic systems, chemists use small molecules with defined hydrophobic cavities that emulate enzyme active site properties to catalyse specific chemical transformations. ${ }^{5-8}$ An exciting area in this research includes the incorporation of transition-metal moieties as redox-active centres that mimic highly evolved ${ }^{9}$ and finely tuned natural photocatalytic systems by catching organic dyes in their pockets. ${ }^{10,11}$ When positively charged, these pockets have important properties in anion encapsulation..$^{12-14}$ As the majority of enzyme substrates are anionic, any replication of their catalysed reactivity under mild biological conditions using synthetic hosts represents a useful advance.

Photocatalytic hydrogen production from water represents an important process in future sustainable solar energy conversion. Inspired by photosynthetic complexes in nature, this process has been realized using a homogeneous reaction environment towards the optimal availability of active catalytic sites for solar hydrogen production. ${ }^{15-18}$ New reaction pathways have emerged for such substrate molecules inside these containers $^{19-21}$ by enhancing the proximity between the substrate and the catalytic centre and by increasing the effective concentration of the reaction within the confined space. ${ }^{22,23}$ This novel, well-elucidated reaction strategy has developed for

State Key Laboratory of Fine Chemicals, Dalian University of Technology, Dalian 116024, P. R. China.E-mail: cyduan@dlut.edu.cn

$\dagger$ Electronic supplementary information (ESI) available: Experimental details, characterization data, as well as additional tables and figures. CCDC 1483351. For ESI and crystallographic data in CIF or other electronic format see DOI: 10.1039/c7ra09285g application in light-driven hydrogen production and has indicated that these supramolecular systems are superior to other relevant systems. Accordingly, the construction of host-guest photosynthetic systems should be a promising approach to increase hydrogen production efficiency. ${ }^{24,25}$

Copper is an earth-abundant and low-cost material that also participates in many biological metabolic processes, for example, photosynthesis and respiration, with various functions. ${ }^{26-29} \mathrm{~A} \mathrm{Cu}^{\mathrm{II}}$ complexes with well-defined coordination chemistry and diverse redox chemistry have attracted extensive attention and have been used as catalysts for various transformations. ${ }^{30-32}$ To our surprise, only a few copper complexes have been used for the electrocatalytic reduction ${ }^{33}$ and oxidation of water. ${ }^{34,35}$ Herein, we report a copper triangular metallomacrocycle $\mathbf{C u}-\mathbf{O B P}$ (where $\mathrm{H}_{2} \mathbf{O B P}=2,2^{\prime}-\left(\left[\left[1,1^{\prime}\right.\right.\right.$-biphenyl $]-4,4^{\prime}$ diylbis(azanylylidene))bis(methanylyl idene))diphenol) encapsulating an organic dye molecule for homogeneous light-driven hydrogen production. To the best of our knowledge, this is the first example of a homogeneous copper metal-organic macrocycle for photo-catalytic hydrogen generation from water (Scheme 1).

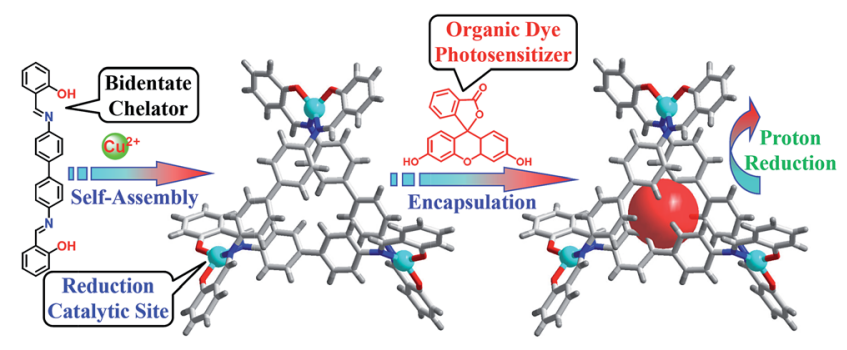

Scheme 1 Procedure for the synthesis of the molecular $\mathrm{Cu}-\mathrm{OBP}$ triangle and construction of the artificial supramolecular system for photocatalytic proton reduction. 
The ligand $\mathrm{H}_{2} \mathbf{O B P}$ and complex $\mathrm{Cu}-\mathbf{O B P}$ were obtained according to previous literature procedures. ${ }^{36}$ Single-crystal X-ray structural analysis indicated that two of three ligands were linked by one metal centre during self-assembly, while the third ligand position on the same side as the other ligands constructed a non- $C_{3}$ symmetry triangular geometry. ${ }^{37-40}$ Due to the comfortable metal $\cdots$ metal distances of approximately $12.2 \AA$, the three ligands overlap to form a double-layer structure with a height of approximately $9.3 \AA$. The structural features of the molecular triangle most likely allow the encapsulation of one planar fluorescein (FI) molecule in the pocket ${ }^{41}$ producing an artificial supramolecular system for the light-driven generation of hydrogen from water. ${ }^{42}$

The solution-phase stability of $\mathbf{C u}-\mathbf{O B P}$ was characterized by electrospray ionisation-mass spectrometry (ESI-MS), revealing an intense peak at $m / z=1362.20$ (Fig. 1). A simple comparison with the simulation results based on natural isotopic abundances suggests that this peak is properly assigned to the singly charged $\left[\mathrm{HCu}_{3}(\mathbf{O B P})_{3}\right]^{+}$species, indicating the formation and stability of the $\mathrm{M}_{3} \mathrm{~L}_{3}$ species in solution. When an equimolar amount of $\mathbf{F l}$ was added into the solution of $\mathbf{C u}-\mathbf{O B P}$, a new intense peak at $\mathrm{m} / \mathrm{z}=1694.28$ was observed, which could clearly attributed to a $\left[\mathrm{HCu}_{3}(\mathbf{O B P})_{3}(\mathbf{F I})\right]^{+}$species. A comparison of the experimentally obtained peak with that obtained via simulation based on natural isotopic abundances confirms the formation of a $1: 1$ stoichiometric host-guest complex species $\mathbf{F l} \subset \mathbf{C u}-\mathbf{O B P}$ in the solution.

Isothermal titration microcalorimetry (ITC) was used to ensure the quantitative accuracy of the titration data and provide insight into the thermodynamics for host-guest complexation. ${ }^{43-45}$ A typical titration curve is shown in Fig. 2a; the enthalpy change $(\Delta H)$ and entropy change $(T \Delta S)$ for $\mathbf{C u}-\mathbf{O B P}$ $\supset \mathbf{F l}$ are -1.5 and $30.0 \mathrm{~kJ} \mathrm{~mol}^{-1}$, respectively, with a good " $n$ " value of 1.0 in the curve fitting by computer simulation using an "independent" model.

Cyclic voltammetry of the molecular $\mathbf{C u}-\mathbf{O B P}$ triangle (1.0 mM) recorded in $\mathrm{CHCl}_{3}$ solution shows the coupled $\mathrm{Cu}^{\mathrm{I}} / \mathrm{Cu}^{0}$ reduction process at approximately $-0.75 \mathrm{~V}(\nu s$. $\mathrm{Ag} / \mathrm{AgCl})$

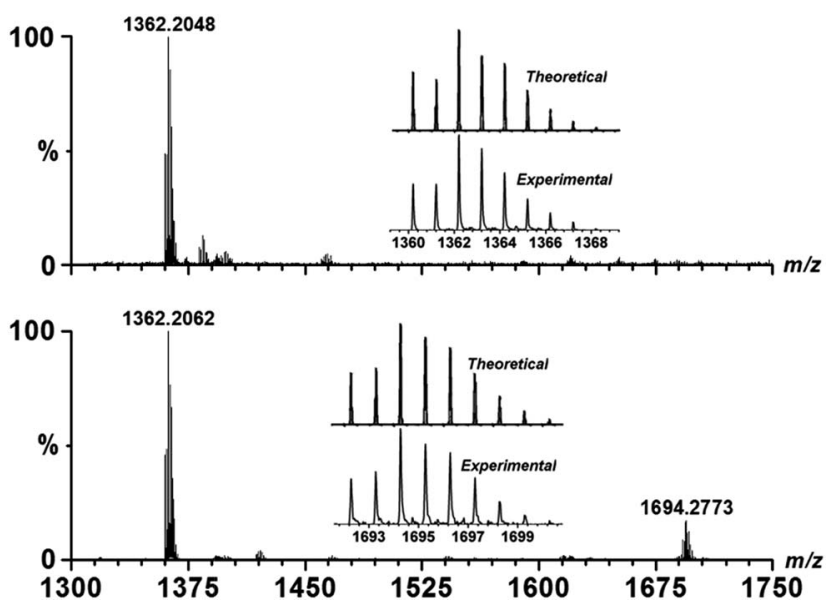

Fig. 1 ESI-MS spectra of $\mathrm{Cu}-\mathrm{OBP}$ in EtOH solution (top) and of $\mathrm{Fl}$ in the aforementioned solution (bottom). The insets show the measured and simulated isotopic patterns at $\mathrm{m} / \mathrm{z}=1362.20$ (top) and 1694.28 (bottom).
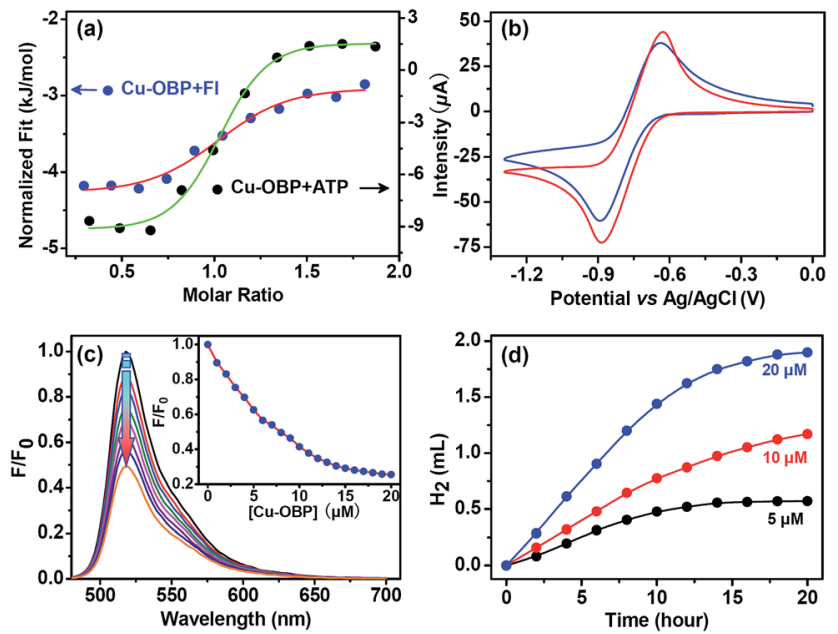

Fig. 2 (a) ITC experiments of $\mathrm{Cu}$-OBP upon addition of Fl or ATP in $\mathrm{EtOH}$ solution, showing the formation of host-guest complex species. (b) Cyclic voltammograms of $0.1 \mathrm{mM} \mathrm{Cu}-\mathrm{OBP}$ (blue line) and $0.3 \mathrm{mM}$ $\mathrm{Cu}-\mathrm{OMP}$ (red line), which is a mononuclear copper complex possessing the same coordination geometry as $\mathrm{Cu}-\mathrm{OBP}$, in $\mathrm{CHCl}_{3}$ containing $0.1 \mathrm{MTBAPF}_{6}$. Scan rate: $100 \mathrm{mV} \mathrm{s}^{-1}$. (c) Set of emission spectra for $\mathrm{Fl}(10 \mu \mathrm{M})$ upon the addition of $\mathrm{Cu}-\mathrm{OBP}$. The inset shows the normalized luminescence vs. [Cu-OBP]. (d) Light-driven hydrogen evolution of systems containing $\mathrm{Fl}(4.0 \mathrm{mM}), \mathrm{NEt}_{3}(15 \% \mathrm{v} / \mathrm{v})$, and $\mathrm{Cu}-\mathrm{OBP}$ in an $\mathrm{EtOH} / \mathrm{H}_{2} \mathrm{O}$ solution $(1: 1, \mathrm{pH}=12.5)$ with the concentration of $\mathrm{Cu}-\mathrm{OBP}$ fixed at $5.0 \mu \mathrm{M}$ (black), $10.0 \mu \mathrm{M}$ (red line), and $20.0 \mu \mathrm{M}$ (blue line).

(Fig. 2b). ${ }^{33,46} \mathrm{The} \mathrm{Cu}^{\mathrm{I}} / \mathrm{Cu}^{0}$ potential falls well within the range of that of proton reduction in aqueous media, indicating that the reduced $\mathbf{C u}-\mathbf{O B P}$ complex is capable of directly reducing protons. ${ }^{46-48}$ The molecular $\mathbf{C u}-\mathbf{O B P}$ triangle is also demonstrated to be an efficient quencher of the $\mathbf{F l}$ excited state. The addition of an equivalent molar ratio of $\mathrm{Cu}-\mathrm{OBP}$ to an $\mathrm{EtOH} /$ $\mathrm{H}_{2} \mathrm{O}$ solution $(1: 1$ in volume, $\mathrm{pH}=12.5$, ensuring the same $\mathrm{pH}$ condition as that of the reaction mixture mentioned below for photocatalytic hydrogen evolution) containing Fl $(10 \mu \mathrm{M})$ quenched approximately $50 \%$ of the Fl emission intensity (Fig. 2c). The quenching behaviour is attributed to the photoinduced electron transfer (PET) process from the excited state $\mathbf{F I}^{*}$ to the redox catalyst $\mathrm{Cu}-\mathbf{O B P}{ }^{49}$

Irradiation of a solution containing Fl $(4.0 \mathrm{mM}), \mathbf{C u}-\mathbf{O B P}$ $(10.0 \mu \mathrm{M})$, and triethylamine $\left(\mathrm{Et}_{3} \mathrm{~N}, 15 \%\right.$ in volume) in an $\mathrm{EtOH} /$ $\mathrm{H}_{2} \mathrm{O}$ (1:1 in volume) solution at $25{ }^{\circ} \mathrm{C}$ resulted in direct hydrogen generation..$^{25,50} \mathrm{~A}$ higher hydrogen production efficiency was achieved at $\mathrm{pH}=12.0-13.0$. Control experiments revealed that the absence of any of these individual components led to failure to produce hydrogen, thus demonstrating that all three species are essential for hydrogen generation. Of course, the artificial system could not function well in the absence of light. When the concentrations of $\mathbf{F l}(4.0 \mathrm{mM})$ and $\mathrm{Et}_{3} \mathrm{~N}(15 \%$ in volume) were fixed, the produced hydrogen volume exhibited a linear relationship with the $\mathbf{C u}-\mathbf{O B P}$ catalyst concentration in the range of $5.0 \mu \mathrm{M}$ to $20.0 \mu \mathrm{M}$ (Fig. 2d). The calculated turnover number (TON) was approximately 1200 moles of hydrogen per mole of catalyst (Fig. 3a). The modified supramolecular system exhibits the highest TON among related homogenous copper/FI 

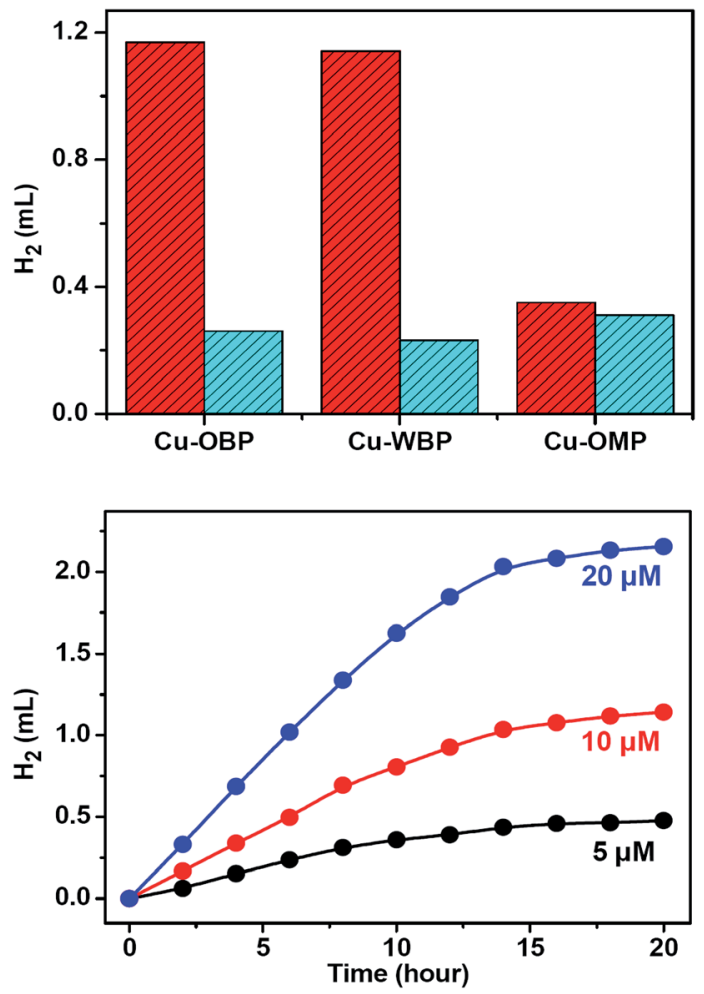

Fig. 3 (a) Produced hydrogen volume by systems containing $\mathrm{Fl}(4.0$ $\mathrm{mM}), \mathrm{Et}_{3} \mathrm{~N}$ (15\% in volume), and redox catalysts (red bars) in $\mathrm{EtOH} / \mathrm{H}_{2} \mathrm{O}$ ( $1: 1$ in volume, $\mathrm{pH}=12.5)$ : $\mathrm{Cu}-\mathrm{OBP}(10.0 \mu \mathrm{M}), \mathrm{Cu}-\mathrm{WBP}(10.0 \mu \mathrm{M}$, in $\mathrm{EtOH} / \mathrm{H}_{2} \mathrm{O}=2: 8$, in volume, $\left.\mathrm{pH}=12.5\right)$, and $\mathrm{Cu}-\mathrm{OMP}(30.0 \mu \mathrm{M})$. The cyan bars show the aforementioned systems in the presence of ATP (4.0 $\mathrm{mM}$ ). (b) Light-driven hydrogen evolution of systems containing $\mathrm{Fl}$ $(4.0 \mathrm{mM}), \mathrm{NEt}_{3}(15 \% \mathrm{v} / \mathrm{v})$ and $\mathrm{Cu}-\mathrm{WBP}$ in an $\mathrm{EtOH} / \mathrm{H}_{2} \mathrm{O}$ solution $(1: 1, \mathrm{pH}=12.5)$ with the $\mathrm{Cu}-\mathrm{WBP}$ concentration fixed at $5.0 \mu \mathrm{M}$ (black), $10.0 \mu \mathrm{M}$ (red line) and $20.0 \mu \mathrm{M}$ (blue line).

systems. This is the first example of a homogeneous copper metal-organic macrocycle for photocatalytic hydrogen generation from water, ${ }^{33,46}$ providing an opportunity for the development of highly efficient copper-based catalysts for photocatalytic proton reduction.

To further determine whether photocatalytic hydrogen evolution occurred inside the pocket of $\mathrm{Cu}-\mathbf{O B P}$ through a typical enzymatic fashion or outside of the pocket in a normal homogeneous manner, an important biomolecule without any suitable redox potential for hydrogen production, adenosine triphosphate (ATP), was chosen as an inhibitor for our enzymatic system. ${ }^{9}$ The inhibition of the photocatalytic reaction was displayed through the addition of this non-reactive species. ${ }^{24}$ Microcalorimetric titration curve generated for $\mathbf{C u}-\mathbf{O B P}$ upon addition of ATP revealed the formation of a host-guest system. The higher $\Delta H\left(-11.0 \mathrm{~kJ} \mathrm{~mol}^{-1}\right)$ and $T \Delta S\left(22.9 \mathrm{~kJ} \mathrm{~mol}^{-1}\right)$ compared to those of the $\mathbf{C u}-\mathbf{O B P} / \mathbf{F l}$ system suggested that ATP could replace $\mathbf{F l}$ and become encapsulated in the pocket of the macrocycle (Fig. 2a). As expected, in the presence of $4.0 \mathrm{mM}$ ATP, photocatalytic hydrogen production by the Fl $(4.0 \mathrm{mM}) /$ $\mathrm{Cu}-$ OBP $(10.0 \mu \mathrm{M}) / \mathrm{Et}_{3} \mathrm{~N}(15 \%)$ system dropped to $20 \%$ of the original value under the same experimental conditions. Thus, the competitive inhibition behaviour was enzymatic-like and suggested that hydrogen production occurred within the cavity of $\mathrm{Cu}-\mathbf{O B P} .^{\mathbf{5 1 , 5 2}}$

To further investigate the potential factors that influence the photocatalytic hydrogen evolution process, a mononuclear copper complex $\mathbf{C u}-\mathbf{O M P}$ (where $\mathrm{H}_{2} \mathbf{O M P}=2$-((phenylimino) methyl)phenol) resembling a corner of the molecular triangular metal-organic macrocycle $\mathbf{C u - O B P}$ was designed and prepared. The ligand HOMP was obtained by a simple Schiff-base reaction of salicylaldehyde with aniline in a $\mathrm{CH}_{3} \mathrm{OH}$ solution. The mononuclear copper complex Cu-OMP was synthesized in approximately $77 \%$ yield by reacting $\mathrm{Cu}\left(\mathrm{BF}_{4}\right)_{2}$ with HOMP in the presence of $\mathrm{NaOH}$ in $\mathrm{CH}_{3} \mathrm{OH}$. ESI-MS spectrum of the solutionphase $\mathrm{Cu}-\mathbf{O M P}$ complex exhibited $\left[\mathrm{NaCu}(\mathbf{O M P})_{2}\right]^{+}$and $\{\mathrm{Na}$ $\left.\left[\mathrm{Cu}(\mathbf{O M P})_{2}\right]_{2}\right\}^{+}$peaks at $m / z=478.11$ and 935.22, suggesting the formation of the mononuclear species in solution. Cyclic voltammetry of Cu-OMP exhibited a broad peak at approximately $-0.75 \mathrm{~V}$ (vs. Ag/AgCl, Fig. 2b), corresponding to the $\mathrm{Cu}^{\mathrm{I}} / \mathrm{Cu}^{0}$ couple. This potential is consistent with the $\mathbf{C u}-\mathbf{O B P}$ triangle and permits the exploration of redox-induced reactions near the $\mathrm{H}_{2} / \mathrm{H}^{+}$couple. Single-crystal structure analysis revealed that the mononuclear $\mathrm{Cu}-\mathbf{O M P}$ copper centre was affixed to two nitrogen and two oxygen atoms. These donors belonged to two bidentate six-membered ring chelators, and the copper centre possessed the same coordination environment as those in $\mathrm{Cu}-$ OBP (Scheme 2). Therefore, Cu-OMP was considered an ideal reference compound for $\mathbf{C u}-\mathbf{O B P}$ in the investigation of photocatalytic hydrogen evolution from water within a supramolecular system.

Photolysis of a solution containing Fl $(4.0 \mathrm{mM})$ and $\mathrm{Cu}-\mathbf{O M P}$ $(30.0 \mu \mathrm{M})$ in a solvent mixture containing $\mathrm{Et}_{3} \mathrm{~N}$ (15\% in volume) and $\mathrm{EtOH} / \mathrm{H}_{2} \mathrm{O}$ (1: 1 in volume) resulted in hydrogen generation under the photocatalytic conditions optimized at $\mathrm{pH}=$ 12.5. The TON was approximately 100 moles of hydrogen per mole of redox catalyst after irradiating for $12 \mathrm{~h}$, and the addition of ATP (4.0 mM) did not obviously change the produced hydrogen volume, demonstrating the normal homogeneous behaviour dynamics of the system (Fig. 3a). The generated
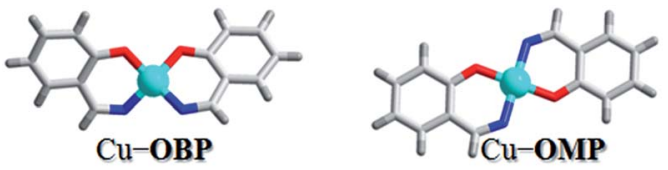

\begin{tabular}{lll}
\hline Bond distances $(\AA)$ & Cu-OBP & Cu-OMP \\
\hline Cu-O in an average & $1.874(6)^{[\mathrm{a}]}$ & $1.878(2)$ \\
$\mathrm{Cu}-\mathrm{N}$ in an average & $1.951(5)$ & $1.997(2)$ \\
$\mathrm{C}-\mathrm{O}$ in an average & $1.303(8)$ & $1.307(2)$ \\
$\mathrm{C}=\mathrm{N}$ in an average & $1.300(6)$ & $1.294(4)$ \\
$\mathrm{C}_{\mathrm{Ar}}-\mathrm{N}$ in an average & $1.419(6)$ & $1.442(4)$ \\
\hline
\end{tabular}

Scheme 2 Square planar coordination geometries of the copper ions in $\mathrm{Cu}-\mathrm{OMP}$ and $\mathrm{Cu}-\mathrm{OBP}$. The copper, oxygen, nitrogen, and carbon atoms are drawn in cyan, red, blue, and grey, respectively. ${ }^{a}$ The numbers in parentheses represent the deviation for the front number. 
hydrogen volume was approximately $30 \%$ of that produced by $\mathrm{Cu}-$ OBP under the same reaction conditions $(10 \mu \mathrm{M} \mathrm{Cu-OBP,} \mathrm{ensuring}$ the same concentration of copper ions), and with an equal copper ion concentration, $\mathrm{Cu}$-OMP exhibited a considerably lower catalytic activity. The superiority of the $\mathrm{Cu}-\mathbf{O B P} / \mathbf{F l} / \mathrm{Et}_{3} \mathrm{~N}$ system over the $\mathrm{Cu}-\mathrm{OMP} / \mathbf{F l} / \mathrm{Et}_{3} \mathrm{~N}$ system is attributed to the new reaction pathways of the $\mathbf{C u}-\mathbf{O B P} / \mathbf{F l} / \mathrm{Et}_{3} \mathrm{~N}$ system and to the increased concentration of the reaction within the confined space..$^{53}$

The application of supramolecular artificial photosynthetic (AP) systems is often limited by aqueous solubility, especially in photocatalytic proton and $\mathrm{CO}_{2}$ reduction. Solubility improvements are thus crucial, a problem that can be overcome by a tailor-made supramolecular flask possessing high solubility in aqueous solution. Therefore, by the introduction of six hydroxymethyl groups, a triangular analogue $\mathrm{Cu}-\mathbf{W B P}$ (where $\mathrm{H}_{2} \mathbf{W B P}=2,2^{\prime}-\left(\left(\left(2,2^{\prime}\right.\right.\right.$-bis(hydroxy methyl)-[1,1'-biphenyl]-4,4'diyl)bis(azanylylidene))bis(methan ylylidene))diphenol) with similar structural features but with a 2,2'-bis(hydroxymethyl) benzidine moiety to substitute the benzidine moiety was designed and prepared. The six hydroxymethyl groups on the periphery of $\mathbf{C u}-\mathbf{W B P}$ provided the assembly with water solubility. ${ }^{54,55}$ The hydroxymethyl substituents not only make the pocket water soluble but also form a hydrophobic environment from the outward direction of the hydroxymethyl groups, thereby allowing easier encapsulation of Fl for light-driven hydrogen production.

The triangular $\mathrm{Cu}-\mathbf{W B P}$ exhibited a suitable reduction potential at $-0.76 \mathrm{~V}$. The solution-phase $\mathrm{Cu}-\mathbf{W B P}$ structure was further characterized by ESI-MS analysis. The intense peaks at $\mathrm{m} / \mathrm{z}=771.65,782.64$ and 793.62 were assigned to $\left[\mathrm{H}_{2} \mathrm{Cu}_{3}(\mathbf{W B P})_{3}\right]^{2+}, \quad\left[\mathrm{HNaCu}_{3}(\mathbf{W B P})_{3}\right]^{2+}$ and $\left[\mathrm{Na}_{2} \mathrm{Cu}_{3}(\mathbf{W B P})_{3}\right]^{2+}$, respectively, by a simple comparison with the simulation results based on natural isotopic abundances, suggesting the formation and stability of the $\mathrm{M}_{3} \mathrm{~L}_{3}$ species in solution. The ESI-MS spectrum of the $\mathrm{Cu}-\mathbf{W B P}$ solution containing an equimolar amount of $\mathbf{F l}$ also exhibited a new peak at $m / z=937.67$, which was assigned to a $\left[\mathrm{H}_{2} \mathrm{Cu}_{3}(\mathbf{W B P})_{3}(\mathbf{F l})\right]^{2+}$ species (Fig. 4), implying
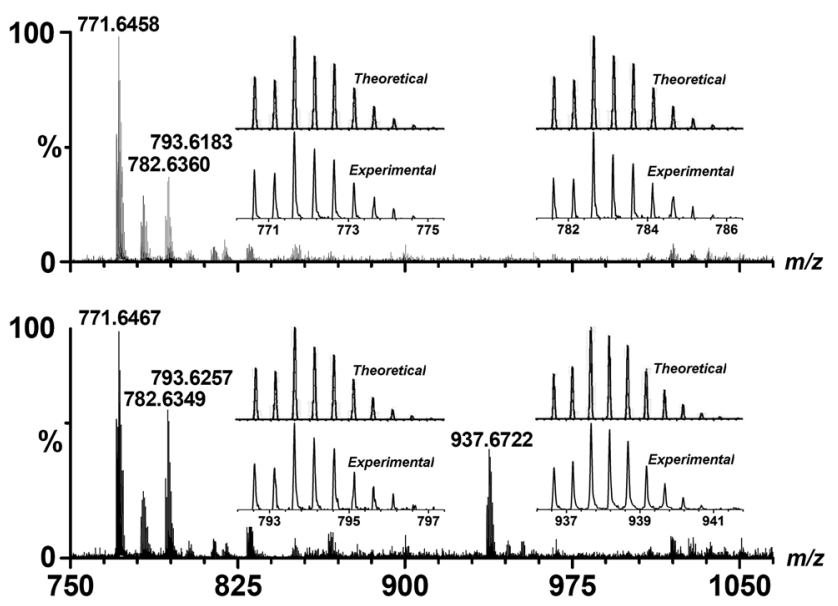

Fig. 4 ESI-MS spectra of $\mathrm{Cu}-\mathrm{WBP}$ in $\mathrm{EtOH}$ solution (top) and of $\mathrm{Fl}$ in the aforementioned solution (bottom). The insets show the measured and simulated isotopic patterns at $\mathrm{m} / \mathrm{z}=771.64,782.63,793.62$ and 937.67, respectively. the formation of a $1: 1$ stoichiometric complex species Fl $\subset$ $\mathrm{Cu}-\mathbf{W B P}$ in solution. In addition, loading an identical amount of the water-soluble $\mathbf{C u}-\mathbf{W B P}$ analogue with the $\mathrm{Cu}-\mathbf{O B P}$ provided the same catalytic efficiency for light-driven hydrogen production. The results of the catalytic experiments suggest that the introduction of water-soluble functional groups does not influence the photo-catalytic properties of the AP system. Even upon increasing the $\mathrm{EtOH} / \mathrm{H}_{2} \mathrm{O}$ volume ratio to $2: 8$, the hydrogen evolution reaction nearly maintained the original reaction rate (Fig. 3), providing a strategy for the construction of water-soluble systems as efficient homogeneous catalysts for photocatalytic proton reduction.

\section{Conclusions}

In summary, we applied our strategy for the construction of $\mathrm{Cu}$ based AP systems for hydrogen generation from water by encapsulating an organic photosensitizer in the pocket of a metal-organic triangle. For the first time, copper ions were introduced into a metal-organic macrocycle as a highly effective visible-light photocatalyst for homogeneous splitting water to hydrogen. The copper triangle exhibited a suitable redox potential for hydrogen production. The results provide an opportunity for the development of highly efficient copperbased supramolecular catalysts for photocatalytic proton reduction. The introduction of hydroxymethyl groups provides aqueous solubility for the supramolecular catalyst without influencing the original photocatalytic properties. The superior activity and stability suggest that this novel approach for the construction of water-soluble supramolecular AP systems as efficient homogeneous catalysts is promising and could be extended to other aqueous chemical transformations.

\section{Conflicts of interest}

The authors declare no conflict of interest.

\section{Acknowledgements}

We are grateful for the National Natural Science Foundation of China (21501019, 21531001, and 21421005).

\section{Notes and references}

1 C. J. Brown, F. D. Toste, R. G. Bergman and K. N. Raymond, Chem. Rev., 2015, 115, 3012-3035.

2 K. Yan and M. Fujita, Science, 2015, 350, 1165-1166.

3 R. J. Hooley, Nat. Chem., 2016, 8, 202-204.

4 D. Zhang, A. Martinez and J. P. Dutasta, Chem. Rev., 2017, 117, 4900-4942.

5 T. K. Hyster, L. Knörr, T. R. Ward and T. Rovis, Science, 2012, 338, 500-503.

6 D. M. Kaphan, M. D. Levin, R. G. Bergman, K. N. Raymond and F. D. Toste, Science, 2015, 350, 1235-1238.

7 Q. Q. Wang, S. Gonell, S. H. A. M. Leenders, M. Dürr, I. Ivanović-Burmazović and J. N. H. Reek, Nat. Chem., 2016, 8, 225-230. 
8 T. R. Cook and P. J. Stang, Chem. Rev., 2015, 115, 7001-7045. 9 X. Jing, C. He, Y. Yang and C. Y. Duan, J. Am. Chem. Soc., 2015, 137, 3967-3974.

10 D. Luo, X. Zhou and D. Li, Angew. Chem., Int. Ed., 2015, 54, 6190-6195.

11 L. Yang, C. He, X. Liu, J. Zhang, H. Sun and H. Guo, Chem.Eur. J., 2016, 22, 5253-5260.

12 P. Ballester, Chem. Soc. Rev., 2010, 39, 3810-3830.

13 D. Zhang, T. K. Ronson, J. Mosquera, A. Martinez, L. Guy and J. R. Nitschke, J. Am. Chem. Soc., 2017, 139, 6574-6577.

14 J. Ayme, J. E. Beves, C. J. Campbell, G. Gil-Ramírez, D. A. Leigh and A. J. Stephens, J. Am. Chem. Soc., 2015, 137, 9812-9815.

15 H. B. Gray and A. W. Maverick, Science, 1981, 214, 12011205.

16 W. Lubitz and W. Tumas, Chem. Rev., 2007, 107, 3900-3903. 17 D. M. Schultz and T. P. Yoon, Science, 2014, 343, 985.

18 A. J. Esswein and D. G. Nocera, Chem. Rev., 2007, 107, 40224047.

19 M. Yoshizawa, M. Tamura and M. Fujita, Science, 2006, 312, 251-254.

20 C. J. Brown, F. D. Toste, R. G. Bergman and K. N. Raymond, Chem. Rev., 2015, 115, 3012-3035.

21 D. M. Dalton, S. R. Ellis, E. M. Nichols, R. A. Mathies, F. D. Toste, R. G. Bergman and K. N. Raymond, J. Am. Chem. Soc., 2015, 137, 10128-10131.

22 D. M. Kaphan, F. D. Toste, R. G. Bergman and K. N. Raymond, J. Am. Chem. Soc., 2015, 137, 9202-9205.

23 J. Zhang, H. Yu, C. Zhang, C. He and C. Y. Duan, New J. Chem., 2014, 38, 3137-3145.

24 C. He, J. Wang, L. Zhao, T. Liu, J. Zhang and C. Y. Duan, Chem. Commun., 2013, 49, 627-629.

25 X. Jing, P. Wu, X. Liu, L. Yang, C. He and C. Y. Duan, New J. Chem., 2015, 39, 1051-1059.

26 C. Dennison, Coord. Chem. Rev., 2005, 249, 3025-3054.

27 N. M. Marshall, D. K. Garner, T. D. Wilson, Y. G. Gao, H. Robinson, M. J. Nilges and Y. Lu, Nature, 2009, 462, 113-116.

28 A. Bhagi-Damodaran, M. A. Michael, Q. Zhu, J. Reed, B. A. Sandoval, E. N. Mirts, S. Chakraborty, P. MoënneLoccoz, Y. Zhang and Y. Lu, Nat. Chem., 2017, 9, 257-263.

29 C. J. K. Wijekoon, S. R. Udagedara, R. L. Knorr, R. Dimova, A. G. Wedd and Z. Xiao, J. Am. Chem. Soc., 2017, 139, 4266-4269.

30 T. Zhang, C. Wang, S. Liu, J. Wang and W. Lin, J. Am. Chem. Soc., 2014, 136, 273-281.

31 M. T. Zhang and T. J. Meyer, J. Am. Chem. Soc., 2013, 135, 2048-2051.

32 R. C. Walroth, K. C. Miles, J. T. Lukens, S. N. MacMillan, S. S. Stahl and K. M. Lancaster, J. Am. Chem. Soc., 2017, 139, 13507-13517.
33 P. Zhang, M. Wang, Y. Yang, T. Yao and L. C. Sun, Angew. Chem., Int. Ed., 2014, 53, 13803-13807.

34 M. K. Coggins, M. T. Zhang, Z. Chen, N. Song and T. J. Meyer, Angew. Chem., Int. Ed., 2014, 53, 12226-12230.

35 A. Zarkadoulas, E. Koutsouri and C. A. Mitsopoulou, Coord. Chem. Rev., 2012, 256, 2424-2434.

36 D. Guo, C. Q. Qian, C. Y. Duan, K. L. Pang and Q. J. Meng, Inorg. Chem., 2003, 42, 2024-2030.

37 M. Schmittel and K. Mahata, Inorg. Chem., 2009, 48, 822-824. 38 T. R. Cook and P. J. Stang, Chem. Rev., 2015, 115, 7001-7045.

39 R. Chakrabarty, P. S. Mukherjee and P. J. Stang, Chem. Rev., 2011, 111, 6810-6918.

40 Z. Jiang, Y. Li, M. Wang, D. Liu, J. Yuan, M. Chen, J. Wang, G. R. Newkome, W. Sun, X. Li and P. Wang, Angew. Chem., Int. Ed., 2017, 56, 11450-11455.

41 J. Zhuang, C. H. Kuo, L. Y. Chou, D. Y. Liu, E. Weerapana and C. K. Tsung, ACS Nano, 2014, 8, 2812-2819.

42 H. Yu, C. He, J. Xu, C. Duan and J. N. H. Reek, Inorg. Chem. Front., 2016, 3, 1256-1263.

43 B. Gómez, V. Francisco, F. Fernández-Nieto, L. Garcia-Rio, M. Martín-Pastor, M. R. Paleo and F. J. Sardina, Chem.-Eur. J., 2014, 20, 12123-12132.

44 S. Kaabel, J. Adamson, F. Topić, A. Kiesilä, E. Kalenius, M. Öeren, M. Reimund, E. Prigorchenko, A. Lõokene, H. J. Reich, K. Rissanen and R. Aav, Chem. Sci., 2017, 8, 2184-2190.

45 W. Zhao, C. Wang, L. Chen, R. Lin, X. Cui, Q. Zhu, Z. Tao and J. Liu, RSC Adv., 2016, 6, 11937-11942.

46 X. Y. Dong, M. Zhang, R. B. Pei, Q. Wang, D. H. Wei, S. Q. Zang, Y. T. Fan and T. C. W. Mak, Angew. Chem., Int. Ed., 2016, 55, 2073-2077.

47 H. I. Karunadasa, C. J. Chang and J. R. Long, Nature, 2010, 464, 1329-1333.

48 V. Artero, M. Chavarot-Kerlidou and M. Fontecave, Angew. Chem., Int. Ed., 2011, 50, 7238-7266.

49 K. M. K. Swamy, S. Ko, S. Kwon, H. N. Lee, C. Mao, J. Kim, K. Lee, J. Kim, I. Shin and J. Yoon, Chem. Commun., 2008, 44, 5915-5917.

50 A. Das, Z. Han, W. W. Brennessel, P. L. Holland and R. Eisenberg, ACS Catal., 2015, 5, 1397-1406.

51 L. Zhao, J. Wei, J. Lu, C. He and C. Duan, Angew. Chem., Int. Ed., 2017, 56, 8692-8696.

52 C. J. Hastings, D. Fiedler, R. G. Bergman and K. N. Raymond, J. Am. Chem. Soc., 2008, 130, 10977-10983.

53 L. Yang, X. Jing, C. He, Z. Chang and C. Duan, Chem.-Eur. J., 2016, 22, 18107-18114.

54 S. Zarra, J. K. Clegg and J. R. Nitschke, Angew. Chem., Int. Ed., 2013, 52, 4837-4840.

55 T. F. Beltrán, R. Llusar, M. Sokolov, M. G. Basallote, M. Jesus Fernández-Trujillo and J. ÁngelPino-Chamorro, Inorg. Chem., 2013, 52, 8713-8722. 